\title{
The effects of temperature on walking and righting in
} temperate and Antarctic crustaceans

\author{
John S. Young ${ }^{1,3, *}$, Lloyd S. Peck ${ }^{2}$ and Thomas Matheson ${ }^{1,4}$ \\ ${ }^{1}$ Department of Zoology, University of Cambridge, Downing Street, \\ Cambridge, CB2 3EJ, UK \\ ${ }^{2}$ British Antarctic Survey, High Cross, Madingley Road, Cambridge, CB3 \\ OET, UK \\ ${ }^{3}$ Current address: Department of Pharmacology, University of Oxford, \\ Mansfield Road, Oxford OX1 3QT, UK \\ ${ }^{4}$ Current address: Department of Biology, University of Leicester, \\ University Road, Leicester LE1 7RH, UK
}
*E-mail:
*Contact telephone:
john.young@pharm.ox.ac.uk
*Contact fax:
$+44(0) 1865271617$
$+44(0) 1865271853$ 
Young, Peck and Matheson. Temperature effects on walking and righting.

\begin{abstract}
Antarctic marine invertebrates live in a cold, thermally stable environment and cannot tolerate large changes in body temperature (i.e. they are stenothermal). Their temperate relatives, by contrast, are eurythermal; living in warmer and thermally more variable environments. Have these different environments influenced how specific behaviours are affected by changes of temperature? This question was addressed in two temperate crustaceans, the decapod Carcinus maenas and isopod Ligia oceanica, and two Antarctic crustaceans, the isopod Glyptonotus antarcticus and amphipod Paraceradocus gibber.
\end{abstract}

The thermal dependence of walking speed was analysed by contrasting the slopes of the linear part of each species' behavioural curve. Over the temperature ranges analysed, the temperature sensitivity of walking speed in the stenotherms was $13-23 \%$ that of the eurytherms when measured in body lengths. $\mathrm{s}^{-1}$.

There was a linear relationship between walking speed and temperature up to $+4.5^{\circ} \mathrm{C}$ in the Antarctic species G. antarcticus and $P$. gibber. Elevating temperature by up to $3.5^{\circ} \mathrm{C}$ above the maximum temperature experienced in the Antarctic $\left(+1^{\circ} \mathrm{C}\right)$, does not lead to an acute breakdown of motor coordination.

We describe for the first time the righting behaviour of $G$. antarcticus. The mean time-to-right tended to a minimum on warming from -2 to $+5^{\circ} \mathrm{C}$, but this trend was not statistically significant.

Our results suggest that the physiological adaptations which permit continued activity at low Antarctic temperatures have resulted in a lower thermal dependence of activity in Antarctic species, compared to related temperate species. 
Young, Peck and Matheson. Temperature effects on walking and righting.

\section{Introduction}

Marine Antarctic invertebrates live at permanently low and very stable temperatures. The annual variation at a depth of $15 \mathrm{~m}$ is less than $3^{\circ} \mathrm{C}(-1.9$ to $+1{ }^{\circ} \mathrm{C}$; Pörtner, 2002). By contrast, marine invertebrates living in the littoral zone of temperate waters experience large daily and seasonal fluctuations of temperature. The daily variation in England, which is the locale from which our study animals were collected, is up to $12^{\circ} \mathrm{C}$, with an annual range of 2 to $23^{\circ} \mathrm{C}$ (Willows, 1987). Populations from closer to the equator almost certainly experience even greater fluctuations than this (e.g. see Gentile and Argano, 2005). Does the range of temperatures throughout which behaviour is performed correlate with the normal range of environmental temperatures experienced by the animals? How are the maximum behavioural rates, and the thermal dependence of the behavioural rates, related to the animals' environmental temperature range?

Behavioural rates increase with temperature in temperate poikilotherms (Lindström and Fortelius, 2001; Symons, 1964; Mellanby, 1939). If experimental temperatures span a sufficient range, however, behavioural rates may exhibit asymmetrical dome-shaped relationships with temperature as torpor sets in at higher temperatures (Bennett, 1990). The relationship between behavioural rate and temperature can be shifted along the temperature axis by acclimating animals to different temperatures (Prosser, 1958). Limited evidence from the lobster H. americanus and the grain weevil S. granarius suggests that a characteristic of acclimation to low temperature is that the maximum behavioural rate achievable is lower than for animals acclimated to higher temperatures (McLeese and Wilder, 1958).

Animals acclimated to higher temperatures therefore have higher thermal dependence of behaviour. For example, the absolute thermal dependence of walking speed of $H$. americanus increases with acclimation temperature (McLeese and Wilder, 1958). The effects of temperature on the behavioural rates of invertebrates living at very high and very low temperatures, or in exceptionally stable thermal environments like the Antarctic, are largely unstudied. Temperature has different effects on the locomotion speeds of two species of limpets that inhabit Antarctic and subAntarctic waters. The locomotion speed of Kerguelenella lateralis increases 
Young, Peck and Matheson. Temperature effects on walking and righting.

upon warming from $2{ }^{\circ} \mathrm{C}$ to $15^{\circ} \mathrm{C}$, then decreases with further warming, and ceases altogether at $30^{\circ} \mathrm{C}$ (Davenport, 1997). In contrast, the locomotion speed of Nacella concinna is negatively correlated with temperature, decreasing as temperature increases from $2^{\circ} \mathrm{C}$ to $14^{\circ} \mathrm{C}$, when the animals become inactive (Davenport, 1997). The species have different thermal niches, and different geographical ranges that overlap at South Georgia which is the southern limit for K. lateralis and the northern limit for $N$. concinna. K. lateralis occurs in middle-shore rock pools, and has a broad thermal niche of -17.8 to $+31.8^{\circ} \mathrm{C}$. In contrast $N$. concinna is confined to the lower shore and experiences temperatures of -12.9 to $+15.6^{\circ} \mathrm{C}$.

We have analysed the effects of temperature on the rates of walking and righting in eurythermal marine crustaceans from the British coast, the decapod Carcinus maenas and the isopod Ligia oceanica, and compared these with the rates for highly stenothermal species from the Antarctic, the isopod Glyptonotus antarcticus and the amphipod Paraceradocus gibber. The isopods Ligia oceanica Linnaeus (suborder: Oniscidea), Glyptonotus antarcticus Eights (suborder: Valvifera) and the amphipod Paraceradocus gibber Andres are all peracarid crustaceans, and are therefore closely related (Schram, 1986). L. oceanica occupies a high intertidal niche (Hewitt, 1907) whereas G. antarcticus and P. gibber are both benthic scavengers (Wägele, 1991; Coleman, 1989). We therefore include comparisons with the more distantly related temperate decapod, Carcinus maenas Linnaeus, which is a benthic scavenger and predator (Ropes, 1968) of similar size to G. antarcticus. Large amphipods and isopods are absent from temperate waters, and reptant decapods are absent from polar seas (Frederich et al. 2001; Thatje et al. 2005). One factor that limits reptant decapods like crabs from surviving in polar waters is their relatively high haemolymph concentrations of magnesium. Magnesium exerts a narcotising effect at neuromuscular junctions and thus restricts ventilatory and circulatory capacity; effects that are exacerbated at low temperatures (e.g. McKenzie et al. 1992; Frederich et al. 2000, 2001; Thatje and Arntz, 2004). In contrast, Natantia including isopods and amphipods are very successful in cold waters because they regulate haemolymph magnesium to low levels (Spicer et al. 1994; Thatje et al. 2005). Our data represent the first quantitative 
Young, Peck and Matheson. Temperature effects on walking and righting.

analyses of locomotion and righting in the Antarctic species, and provide insights into the adaptations that permit poikilotherms to perform normal behaviours in extreme environments.

\section{Materials and Methods}

\section{Collection and housing of animals}

C. maenas (30-50mm in length) were obtained from Wells-Next-The-Sea (U.K.) using baited traps. They were housed in $40 \times 80 \times 16 \mathrm{~cm}$ aquaria containing stones and artificial seawater (in $\mathrm{mM}^{-1}: \mathrm{Cl}^{-}, 541.6 ; \mathrm{Na}^{+}, 465.2$; $\mathrm{Mg}^{2+}, 54.3 ; \mathrm{SO}_{4}^{-}, 28.1 ; \mathrm{Ca}^{2+}, 11.9 ; \mathrm{K}^{+}, 10.5 ; \mathrm{CO}_{2}^{-}, 4.4 ; \mathrm{B}^{3+}, 0.5 ; \mathrm{Br}^{-}, 0.03$; Kent Sea Salt, Kent Marine Inc.), which was aerated and filtered. They were fed on dead fish and were maintained at $+4^{\circ} \mathrm{C}$.

Specimens of L. oceanica (22-28mm in length) were obtained from a tidal wall at Wells-Next-The-Sea. They were housed individually in containers $(8.5 \mathrm{~cm}$ in diameter $\times 6.5 \mathrm{~cm}$ tall $)$ lined with seawater-moistened tissue paper, were fed on vegetable peelings and were maintained at $+4^{\circ} \mathrm{C}$.

G. antarcticus Eights $(60-110 \mathrm{~mm}$ in length) and P. gibber Andres (33-51mm in length) were taken from baited traps at Rothera $\left(67^{\circ} 34^{\prime} \mathrm{S}\right.$, $68^{\circ} 08^{\prime} \mathrm{W}$ ) and Palmer $\left(64^{\circ} 46^{\prime} \mathrm{S}, 6^{\circ} 03^{\prime} \mathrm{W}\right)$ Stations (Antarctica) and transported by ship to the U.K. where they were maintained together in a flow-through seawater aquarium at 0 to $+1^{\circ} \mathrm{C}$. Salinity was maintained at 33 to $36 \mathrm{psu}$ and a $12 \mathrm{~h}$ light : $12 \mathrm{~h}$ dark regime was followed. Transit time was 8 weeks, during which the animals were held in a cooled recirculating seawater aquarium at $0 \pm 1^{\circ} \mathrm{C}$. Animals were fed on dead fish and krill, and their condition was monitored daily. During transport, mortality was less than $10 \%$.

All animals of each species were housed in holding tanks prior to and between experiments, with fewer than 10 animals of the same species housed together. C. maenas were maintained in an aquarium measuring $21 \mathrm{x}$ $21 \times 31 \mathrm{~cm}$. L. oceanica were housed individually in their normal holding containers. G. antarcticus and P. gibber were maintained in a part of the experimental tank, measuring $40.5 \times 75 \times 22 \mathrm{~cm}$ which was divided from the experimental section by netting. All species were starved during the course 
Young, Peck and Matheson. Temperature effects on walking and righting.

of the experiments. C. maenas, G. antarcticus and P. gibber - were held in at least $15 \mathrm{~cm}$ depth of aerated and filtered seawater.

The experimental tanks measured $26 \times 42 \times 12 \mathrm{~cm}$ for C. maenas and L. oceanica, and $40.5 \times 75 \times 22 \mathrm{~cm}$ for G. antarcticus and P. gibber. The depth of seawater was $10 \mathrm{~cm}$ (C. maenas and L. oceanica) or $20 \mathrm{~cm}$ (G. antarcticus and $P$. gibber). Aeration and filtration was suspended during experiments to prevent any currents likely to influence behaviour.

\section{Experimental regime}

Animals of all the species were progressively cooled or warmed in a 5- or 6day temperature series, and their behaviours measured. The Antarctic species were never exposed to temperatures greater than $5^{\circ} \mathrm{C}$. This was to reduce the likelihood of temperature-induced mortality, as G. antarcticus show only $67 \%$ survival if exposed to $11^{\circ} \mathrm{C}$ for only 5 h (Wells, 1979). C. maenas were tested between -2.5 and $+23^{\circ} \mathrm{C}$, and L. oceanica were tested between -2.5 and $+8.5^{\circ} \mathrm{C}$ (righting experiments) or -2.5 and $+7.2^{\circ} \mathrm{C}$ (walking experiments).

Experiments were conducted in controlled-temperature rooms. For C. maenas and L. oceanica the experimental temperature was achieved by changing the temperature of the room. For G. antarcticus and P. gibber the room temperature was maintained at a constant $-2^{\circ} \mathrm{C}$, and the experimental temperature was achieved using a thermocirculator (Grant LTD 20G), which pumped ethylene glycol around the jacketed experimental tank. The temperature for each trial was set at the end of the previous day's observations. It took no more than $2 \mathrm{~h}$ for the temperature of the seawater to match the desired value.

Experiments were conducted daily and took $2 \mathrm{~h}$, leaving at least $22 \mathrm{~h}$ between them. Experiments were carried out throughout the day, in a similar way for all species. Diurnal patterns in the behavioural responses, if present, may have contributed to the variability of the data, but cannot have biased systematically the behavioural variables that were measured. Behaviours were filmed using a tripod-mounted camcorder (Sony TRV620E), with a time code added (FOR-A VTG-33) when the $8 \mathrm{~mm}$ cassettes were duplicated (JVC HR-S7722EK) onto S-VHS tapes for analysis. 
Young, Peck and Matheson. Temperature effects on walking and righting.

\section{Righting}

A righting reflex was elicited by turning animals (C. maenas, G. antarcticus and L. oceanica) upside-down and placing them with their dorsal surface level to the substratum. This was repeated 5 times, with a 10 s interval between rightings. The time-to-right was measured as the time between the initiation of the species-specific righting behaviour and its completion. For definitions of these start and end points, see Figs $1-3$.

For $G$. antarcticus the effect of successive righting attempts was assessed: (A) at temperatures within the environmental temperatures experienced $\left(-2\right.$ to $\left.+1.5^{\circ} \mathrm{C}\right)$; (B) at temperatures greater than those experienced in the animal's environment $\left(+1.5\right.$ to $\left.5^{\circ} \mathrm{C}\right)$.

L. oceanica and C. maenas were tested at temperatures of 0.5 to $8.5^{\circ} \mathrm{C}$ and 0 to $22.8^{\circ} \mathrm{C}$, respectively.

\section{Walking}

This study measures walking rates adopted by the animals in response to gentle tactile stimuli. To elicit walking, a tactile stimulus was given to the uropods (L. oceanica) or to one of the dactyls of the posterior-most pereopods (C. maenas, G. antarcticus and P. gibber). The animal was allowed to walk at its preferred speed until the wall of tank was reached. Following a 10 s pause, the animal was turned by $180^{\circ}$ and the procedure was repeated in the opposite direction. This was repeated until the animal travelled a distance of 50 to 60 body lengths.

Animals of all species generally walked in a straight line, but walking bouts which included deviation of more than $30^{\circ}$ were not included in the analysis. $P$. gibber walk while lying on their sides (and therefore use only those legs on the downward side), so any bout in which the animal walked against the wall of the tank, allowing use of all legs, was not included in the analysis. C. maenas generally walk sideways so walking bouts including backwards or forwards movement were not analysed. Walking speeds are reported as both $\mathrm{ms}^{-1}$ and body lengths. $\mathrm{s}^{-1}$, although for C. maenas the term 'body length' actually refers to 'body width', which was 
Young, Peck and Matheson. Temperature effects on walking and righting.

the maximum width of the carapace. Measurements of body size (both length and width) do not include antennae or legs.

Data were tested for normality and homogeneity of variance prior to statistical analysis.

\section{Results}

If cooled below $0^{\circ} \mathrm{C}$, both temperate species, Carcinus maenas and Ligia oceanica became inactive and entered a state of torpor. This was reversed on warming. If the temperature was lowered below $-2{ }^{\circ} \mathrm{C}$ for $24 \mathrm{~h}, 50 \%$ of animals died $(\mathrm{n}=8)$. Animals behaved normally between 0 and $23^{\circ} \mathrm{C}$, the maximum temperature tested. In contrast, both Antarctic species were active at temperatures as low as $-2.5^{\circ} \mathrm{C}$ and up to $+5^{\circ} \mathrm{C}$, which was the maximum temperature at which their behavioural rates were assessed. Animals that were kept within this temperature range had no mortality.

\section{Righting}

All animals righted themselves in a species-specific way. For C. maenas, an animal placed on its dorsal surface brought its fifth (most posterior) pair of pereopods anteriorly and dorsally before rotating the legs and using the flattened dactyls to push against the substratum. The animal rotated its carapace around a posterior axis (dashed line, Fig. 1).

L. oceanica righted themselves by extending their uropods and antennae, and arching their body to raise it from the substratum. By simultaneously pushing against the substratum with one antenna while withdrawing the other, the animal rolled laterally. The pereopods on one side of the body pushed on the substratum so that the animal rotated along a longitudinal axis (dashed line, Fig. 2).

The Antarctic isopod G. antarcticus righted by extending the fourth pair of pereopods until the dactyls pressed against the substratum underneath the dorsal surface of the animal. Rapid extension of these pereopods against the substratum rotated the posterior end of the animal by more than $90^{\circ}$ anteriorly. The animal walked forward with the other pereopods to complete the righting behaviour (Fig. 3). 
Young, Peck and Matheson. Temperature effects on walking and righting.

At temperatures below $1.5^{\circ} \mathrm{C}$ there was no significant change in the time-to-right of C. maenas and L. oceanica for successive attempts throughout the course of a trial, whereas the time-to-right of G. antarcticus decreased with successive attempts (Fig. 4A).

At temperatures between 1.5 and $5.0^{\circ} \mathrm{C}$, there was no significant change in the time-to-right of C. maenas or G. antarcticus, but the time-toright declined with successive attempts in L. oceanica (Fig. 4B). Interanimal variability was relatively low for $C$. maenas at both temperatures (Fig. 4A,B). Variability for G. antarcticus was lower at low temperatures than at higher temperatures, whereas for L. oceanica, variability was greater at the lower temperatures (Fig. 4A,B).

Increasing the temperature reduced significantly the mean time-toright of both temperate species. The mean time-to-right tended to a minimum; from $5 \mathrm{~s}$ at $0^{\circ} \mathrm{C}$ to $1.5 \mathrm{~s}$ at $23^{\circ} \mathrm{C}$ in C. maenas (Fig. 5A), and from $30.7 \mathrm{~s}$ at $0.5^{\circ} \mathrm{C}$ to $1.7 \mathrm{~s}$ at $8.5^{\circ} \mathrm{C}$ in L. oceanica (Fig. 5B). Although there was a similar trend for G. antarcticus (Fig. 5C) this was not significant, with mean time-to-right remaining at $12 \pm 5 \mathrm{~s}$ between $-2.5^{\circ} \mathrm{C}$ and $+4.5^{\circ} \mathrm{C}$. Animals of all 3 species were active throughout the range of temperatures tested.

The large variation in the mean time-to-right of both $L$. oceanica and G. antarcticus is explained by the long times taken to right by some individual animals. On occasions, animals tried repeatedly to right but appeared unable to generate sufficient force to rotate the body and complete the behaviour.

\section{Walking}

The four species walk in very different ways governed in part by their body shape. C. maenas, L. oceanica and G. antarcticus are dorsal-ventrally flattened. C. maenas generally walk sideways. L. oceanica and G. antarcticus walk forwards. For G. antarcticus, the posterior-most four pairs of pereopods, which are relatively short (see e.g. Fig. 3A) contribute very little to walking on a flat surface. P. gibber is flattened laterally and walks with either the left or right side of its body against the substratum. While the pereopods down one side of its body move the animal along, the legs on the opposite side play no role in walking. 
Young, Peck and Matheson. Temperature effects on walking and righting.

Increasing the temperature affected the rate of walking of all four species. The mean walking rate of $C$. maenas tended to a maximum upon warming from $0^{\circ} \mathrm{C}$, the lowest temperature at which C. maenas was active. This relationship could be fitted with an equation of the form:

$$
\text { speed }=\mathrm{a}\left(1-\mathrm{e}^{-\mathrm{b} \cdot \text { temperature }}\right)
$$

The maximum rate was reached at $10^{\circ} \mathrm{C}$ and maintained to the experimental maximum of $23^{\circ} \mathrm{C}$ (Fig. 6). The walking rate of L. oceanica increased linearly throughout the test temperatures between 1.5 and $7^{\circ} \mathrm{C}$. The walking rate of $P$. gibber also increased linearly between the test temperatures ranging from -2.5 to $+4.5^{\circ} \mathrm{C}$. There was a similar trend for G. antarcticus (Fig. 6) but this was not significant, possibly because of the relatively large variation in the walking speed between individuals.

The thermal dependence of walking speed was analysed by contrasting the slopes of the linear part of each species' behavioural curve (i.e. the slopes of the relationships between temperature and walking speed; see Fig. 6). The significant effect of body length on walking speed (all species grouped, linear regression, walking speed in $\mathrm{ms}^{-1}: F_{1,273}=110.40$, $\mathrm{r}^{2}=0.29, P<0.001$; body lengths. $\mathrm{s}^{-1}: F_{1,273}=11.54, \mathrm{r}^{2}=0.04, P<0.01$ ) was first removed, and the analysis carried out on the unstandardised residuals (Fig. 7A,B). Changes in temperature had a greater effect on walking speed in the eurytherm L. oceanica than in the stenotherm G. antarcticus (walking speed in $\mathrm{ms}^{-1}$ : Kruskal-Wallis, $\chi^{2}=7.18$, $\mathrm{df}=1, P<0.001$; walking speed in body lengths. $\mathrm{s}^{-1}$ : Kruskal-Wallis, $\chi^{2}=9.53, \mathrm{df}=1, P<0.01$ ). Changes in temperature also had a greater effect on walking speed in the second eurytherm $C$. maenas than in G. antarcticus (walking speed in $\mathrm{ms}^{-1}$ : Kruskal-Wallis, $\chi^{2}=9.60, \mathrm{df}=1, P<0.01$; walking speed in body lengths. ${ }^{-1}$ : Kruskal-Wallis, $\left.\chi^{2}=9.60, \mathrm{df}=1, P<0.01\right)$. There was a significant difference between the two eurytherms, C. maenas and L. oceanica when walking speed was measured in $\mathrm{ms}^{-1}$ (Kruskal-Wallis, $\chi^{2}=6.00, \mathrm{df}=1, P<0.05$ ), but not when measured in body lengths. ${ }^{-1}$ (Kruskal-Wallis, $\chi^{2}=0.18, \mathrm{df}=1, P=\mathrm{NS}$ ). There was no significant difference between the two stenotherms, G. antarcticus and $P$. gibber (walking speed in $\mathrm{ms}^{-1}$ : Kruskal-Wallis, $\chi^{2}=3.48, \mathrm{df}=1, P=\mathrm{NS}$; walking speed in body lengths. $\mathrm{s}^{-1}$ : Kruskal-Wallis, $\chi^{2}=0.12$, $\mathrm{df}=1, P=\mathrm{NS}$ ). 
Young, Peck and Matheson. Temperature effects on walking and righting.

Over the temperature ranges analysed, the temperature sensitivity of walking speed in the stenotherms was $13-23 \%$ that of the eurytherms when measured in body lengths. $\mathrm{s}^{-1}$ (overall medians; C. maenas and L. oceanica: 0.13 and 0.16 body lengths. $\mathrm{s}^{-1}$ per ${ }^{\circ} \mathrm{C}$; G. antarcticus and P. gibber: 0.02 and 0.03 body lengths. $\mathrm{s}^{-1}$ per ${ }^{\circ} \mathrm{C}$, respectively), and $19-46 \%$ that of eurytherms when measured in $\mathrm{ms}^{-1}$ (C. maenas and L. oceanica: 0.0052 and $0.0033 \mathrm{~ms}^{-1}$ per ${ }^{\circ} \mathrm{C}$; G. antarcticus and P. gibber: 0.0010 and $0.0015 \mathrm{~ms}^{-1}$ per ${ }^{\circ} \mathrm{C}$, respectively).

\section{Discussion}

Behavioural rates were assessed for temperate and Antarctic crustaceans to understand how the behaviour of animals from stable or variable thermal environments responds to different temperatures. Differences in the way behaviours are performed mean that caution should be taken when absolute behavioural rates of different species are compared. The four species of crustacean right themselves and walk in different ways due to the inherent differences in morphology between amphipods, decapods and isopods. Assessments of the effects of temperature on the change in behavioural rates are, however, not biased by inter-specific differences in morphology.

\section{Righting}

The time-to-right of $C$. maenas tended to a minimum on warming from 0 to $22.8^{\circ} \mathrm{C}$. The time-to-right of the isopods $L$. oceanica and G. antarcticus also decreased on warming, but the trend was not significant for either species probably because of considerable variation between animals (Fig. 5). The large intraspecific variation in the time-to-right of the isopods compared to C. maenas may be due to the way in which they right themselves, which involves exerting force laterally (e.g. Fig. 2). By contrast, for C. maenas the centre of mass appears to be over the legs that push against the substratum (Fig. 1), perhaps reducing the incidence of a loss of contact. The loss of contact between leg and substrate experienced by the isopods is less likely to occur in their more uneven natural environment. 
Young, Peck and Matheson. Temperature effects on walking and righting.

Walking speed was positively and linearly correlated to temperature in $L$. oceanica, G. antarcticus and P. gibber across the range of temperatures tested (Fig. 6). For G. antarcticus and P. gibber test temperatures spanned the normal environmental range encountered by the animals. As L. oceanica in the littoral zone of temperate coastlines experience summer temperatures of up to $23^{\circ} \mathrm{C}$ in England (Willows, 1987) and greater elsewhere (Gentile and Argano, 2005), behaviours are likely to continue up to at least this temperature. It is likely that the maximum behavioural rates observed here at $7.2^{\circ} \mathrm{C}$ were below the maximum rates that the animal can attain.

A key difference between the Antarctic and temperate species is that Antarctic species are able to move at temperatures as low as $-2.5^{\circ} \mathrm{C}$, whereas the temperate species enter behavioural torpor at $0^{\circ} \mathrm{C}$ and have $50 \%$ mortality when exposed briefly to temperatures of $-2^{\circ} \mathrm{C}$. This adaptation to low environmental temperatures is, however, only partial, as maximum rates for the Antarctic species do not occur within the normal environmental temperature range of -1.9 to $+1{ }^{\circ} \mathrm{C}$ (Pörtner, 2002), but at the maximum experimental temperature of $4.5^{\circ} \mathrm{C}$. This is quite different to the thermal sensitivity of the Antarctic and sub-Antarctic limpet Nacella concinna which locomotes most rapidly at $2{ }^{\circ} \mathrm{C}$; the mid-point of its environmental temperature range $\left(-12.9\right.$ to $+15.6^{\circ} \mathrm{C}$; Davenport, 1997). As G. antarcticus and $P$. gibber show no reduction in behavioural rate as temperature is increased to $4.5^{\circ} \mathrm{C}$, this implies that the rate must fall rapidly between $5^{\circ} \mathrm{C}$ and $11^{\circ} \mathrm{C}$, which is the upper temperature at which G. antarcticus show $33 \%$ mortality after only $5 \mathrm{~h}$ exposure (Wells, 1979). This suggests that there is a narrower range of temperatures throughout which Antarctic crustaceans can perform behaviours in comparison to related temperate species. The limpet $N$. concinna has a similarly reduced range of temperatures throughout which locomotion is performed (from 2 to $14^{\circ} \mathrm{C}$ ) when compared to its temperate relative Kerguelenella lateralis (from 2 to $30^{\circ} \mathrm{C}$, Davenport, 1997). Antarctic fish show a similar trend (Somero and DeVries, 1967).

Temperate species acclimated to lower temperatures also have a reduced range of temperatures throughout which behaviour is performed (e.g. McLeese and Wilder, 1958; Barlow and Kerr, 1969), suggesting that a 
Young, Peck and Matheson. Temperature effects on walking and righting.

consequence of adaptations that permit behaviours at low temperatures is a reduction in the range of temperatures throughout which behaviours can be elicited an overall reduction in thermal scope (Somero et al. 1996; Wilson et al. 2001).

There was a lower temperature dependence of the walking rate in the Antarctic isopod G. antarcticus than in its temperate relative L. oceanica in the linear parts of their respective ranges $\left(-2\right.$ to $+5^{\circ} \mathrm{C}$ for the Antarctic species, and 0 to $7^{\circ} \mathrm{C}$ for the temperate species) (Fig. 7). The rates of locomotion of sub-Antarctic limpets also have a lower temperature dependence than their temperate relatives (Davenport, 1997), as do temperate animals acclimated to lower temperatures (e.g. McLeese and Wilder, 1958; Barlow and Kerr, 1969). All these data suggest that a consequence of adaptations to being active at lower temperatures is a reduced thermal dependence. Whether such reduced thermal dependence of behaviour represents an advantage or a disadvantage is unknown. The food available to Antarctic scavengers like G. antarcticus and P. gibber is unlikely to arrive at the same time as the slight seasonal rise in sea temperatures and primary productivity, and this uncoupling of temperature and food availability (Clarke, 1988) may be an important factor in explaining the low temperature dependence of behaviour in Antarctic poikilotherms.

At temperatures between 10 and $22.8^{\circ} \mathrm{C}$, rates of walking and the time taken to right were independent of temperature in eurythermal $C$. maenas (Fig. 6). This is consistent with the thermal dependence of walking of American lobsters, Homarus americanus, (McLeese and Wilder, 1958) and freshwater crayfish Astacus astacus (Kivivuori, 1980). The implication of maintaining behavioural rates throughout summer water temperatures of 10 to $25^{\circ} \mathrm{C}$ (Barnes and Hughes, 1999) is that animals may maximise reproductive success by maintaining a high behavioural capability over a wide range of high temperatures. It also follows that an animal should remain relatively inactive during periods of limited food availability, thereby reducing energy expenditure. For C. maenas this is achieved by the rapid fall off in walking rates at temperatures below $10^{\circ} \mathrm{C}$ (Fig. 6). The consequence of the high thermal dependence of behaviour between 0 and 
Young, Peck and Matheson. Temperature effects on walking and righting.

$10^{\circ} \mathrm{C}$ will be a reduced behavioural output and reduced energy loss as water temperature, and food availability, decrease.

High haemolymph concentrations of magnesium depress neuromuscular transmission in crustacea (Spicer et al. 1994), increase thermal sensitivity and reduce metabolic rate in the cold (Frederich et al. 2000). The narcotising effect of haemolymph $\mathrm{Mg}^{2+}$ levels (Pantin, 1946) becomes more pronounced at lower temperatures (McKenzie et al. 1992) and this is one explanation for the paucity of reptant decapods at high latitudes (but see also Thatje et al. 2003).

Although haemolymph concentrations of magnesium have not been reported for G. antarcticus or P. gibber, the slower rates of behaviour of these animals compared to the temperate species are unlikely to be explained by relatively higher haemolymph concentrations of magnesium. For example, although $C$. maenas has a low haemolymph concentration of $\mathrm{Mg}^{2+}$ (12-20 mmol.1 ${ }^{-1}$; Frederich et al. 2000) for a reptant decapod (average 30-50 mmol. $\mathrm{I}^{-1}$; Frederich et al. 2000), concentrations in the Antarctic peracarids are likely to be 10 -fold less than this. Three lines of evidence support this prediction. First, those amphipods in which haemolymph $\mathrm{Mg}^{2+}$ has been measured have very low concentrations $\left(1.3-3 \mathrm{mmol}^{-1} \mathrm{I}^{-1}\right.$ Spicer et al. 1994), and both amphipods and isopods can down-regulate haemolymph $\mathrm{Mg}^{2+}$ concentration (Thatje et al. 2005). Second, G. antarcticus and $P$. gibber have a lower thermal dependence of behaviour than does $C$. maenas, a characteristic which is generally correlated with lower haemolymph $\mathrm{Mg}^{2+}$ levels (Frederich et al. 2000). Third, the effect of high haemolymph concentrations of $\mathrm{Mg}^{2+}$ in inducing torpor is enhanced at low temperatures (Lagerspetz and Tiiska, 1996). This suggests that crustacea with high haemolymph $\mathrm{Mg}^{2+}$ concentrations should enter cold torpor at temperatures that are higher than those which elicit torpor in species with low haemolymph $\mathrm{Mg}^{2+}$ concentrations. If haemolymph $\mathrm{Mg}^{2+}$ levels were higher in the Antarctic species, it would be difficult to explain our observation that these animals remain active at temperatures as low as $-2.5^{\circ} \mathrm{C}$ whereas $C$. maenas enters torpor at the warmer temperature of $0^{\circ} \mathrm{C}$. 
Young, Peck and Matheson. Temperature effects on walking and righting.

\section{Acknowledgments}

This work was supported by a BBSRC Studentship to J.S.Y. We thank the staff of Rothera and Palmer Stations for collection of animals and Lucy Conway for assistance with animal transport and maintenance. 
Young, Peck and Matheson. Temperature effects on walking and righting.

\section{References}

Barlow CA, Kerr WD (1969) Locomotory responses to temperature in the grain weevil, Sitophilus granarius (L.) (Coleoptera: Curculionidae). Can J Zoology 47:217-224

Barnes RSK, Hughes RN (1999) An Introduction to Behavioural Ecology. Third Edition. Blackwell Science, Oxford, 286pp

Bennett AF (1990) Thermal dependence of locomotor capacity. Am J Physiol 259:253-258

Clarke A (1988) Seasonality in the Antarctic environment. Comp Biochem Physiol B 90:461-474

Coleman CO (1989) Burrowing, grooming and feeding-behaviour of Paraceradocus, an Antarctic amphipod genus (Crustacea). Polar Biol 10:43-48

Davenport JA (1997) Comparisons of the biology of the intertidal subantarctic limpets Nacella concinna and Kerguelenella lateralis. J Moll Stud 63:39-48

Frederich M, Sartoris FJ, Arntz WE, Pörtner H-O (2000) Haemolymph $\mathrm{Mg}^{2+}$ regulation in decapod crustaceans: physiological correlates and ecological consequences in polar areas. J Exp Biol 203:1383-1393

Frederich M, Sartoris FJ, Pörtner H-O (2001) Distribution patterns of decapod crustaceans in polar areas: a result of magnesium regulation? Polar Biol 24:719-723

Gentile G, Argano R (2005) Island biogeography of the Mediterranean sea: the species-area relationship for terrestrial isopods. J Biogeog $32: 1715-1726$

Hewitt CG (1907) Ligia. XIV. In: Herdman WA (ed.) Liverpool Marine Biology Committee. L.M.B.C. memoirs on typical British marine plants and animals. Williams and Norgate, London, 37pp

Kivivuori L (1980) Effects of temperature and temperate acclimation on the motor and neural functions in the crayfish Astacus astacus L. Comp Biochem Physiol 65A:297-304

Lagerspetz KYH, Tiiska A (1996) Why are some substances more toxic for Dapnia magna at low temperatures? Why magnesium? In: Adaptations to Stress in Aquatic and Terrestrial Ecosystems, 
Young, Peck and Matheson. Temperature effects on walking and righting.

European Society for Comparative Physiology and Biochemistry, $17^{\text {th }}$ Annual Conference, Abstracts, pp. 185

Lindström M, Fortelius W (2001) Swimming behaviour in Monoporeia affinis (Crustacea: Amphipoda) - dependence on temperature and population density. J Exp Mar Biol Ecol 256:73-83

McKenzie JD, Colow P, Clyde J, Miles A, Dickinson R, Lieb WR, Franks NP (1992) Effects of temperature on the anaesthetic potency of halothane, enflurane and ethanol in Daphnia magna (Cladocera: Crustacea). Comp Biochem Physiol 101C:15-19

McLeese DW, Wilder DG (1958) The activity and catchability of the lobster (Homarus americanus) in relation to temperature. J Fish Res $\mathrm{Bd}$ Canada 15:1345-1354

Mellanby K (1939) Low temperature and insect activity. Proc R Soc Lond B $127: 473-486$

Pantin CFA (1946) Notes on Microscopical Techniques for Zoologists. Cambridge University Press, Cambridge, 75pp

Pörtner H-O (2002) Climate variations and the physiological basis of temperature dependent biogeography: systemic to molecular hierarchy of thermal tolerance in animals. Comp Biochem Physiol A $132: 739-761$

Prosser CL (1958) General Summary: The nature of physiological adaptation. In: Prosser CL (ed.) Physiological Adaptation. Society of General Physiologists, American Physiology Society, Washington, D.C, pp 167-180

Ropes JW (1968) The feeding habits of the green crab, Carcinus maenas (L.). Fish Bull Wildlife Service US 67:183-203

Schram FR (1986) Crustacea. Oxford University Press, Oxford, 606pp

Somero GN, DeVries AL (1967) Temperature tolerance of some Antarctic fishes. Science 156:257-258

Somero GN, Dahlhoff E, Lin JJ (1996) Stenotherms and eurytherms: mechanisms establishing thermal optima and tolerance ranges. In: Johnston IA, Bennett AF (eds.) Animals and temperature: phenotypic and evolutionary adaptation. Society for Experimental 
Young, Peck and Matheson. Temperature effects on walking and righting.

Biology Seminar Series 59, Cambridge University Press, Cambridge, $435 \mathrm{pp}$

Spicer JI, Morritt D, Taylor AC (1994). Effect of low temperature on oxygen uptake and haemolymph ions in the sandhopper Talitrus saltator (Crustacea: Amphipoda). J Mar Biol Ass UK 74:313-321.

Symons PEK (1964) Behavioural responses of the crab Hemigrapsus oregonensis to temperature, diurnal light variation, and food stimuli. Ecology 45:580-591

Thatje S, Arntz WE (2004) Antarctic reptant decapods: more than a myth? Polar Biol. 27:195-201.

Thatje S, Schnack-Schiel S, Arntz WE (2003) Developmental trade-offs in Subantarctic meroplankton communities and the enigma of low decapod diversity in high southern latitudes. Marine Ecol - Prog Ser 260:195-207

Thatje S, Anger K, Calcagno JA, Lovrich GA, Pörtner HO, Arntz WE (2005) Challenging the cold: crabs reconquer the Antarctic. Ecology $86: 619-625$.

Wägele JW (1991) Antarctic isopoda Valvifera. Volume 2. In: Wägele JW, Sieg J (eds.) Synopses of the Antarctic Benthos. Koeltz Scientific Books, Koenigstein, 213pp

Wells RM (1979) The lethal temperatures of Antarctic marine invertebrates.

N. Z. Ant Records 1:9-13

Willows RI (1987) Population and individual energetics of Ligia oceanica (L.) (Crustacea: Isopoda) in the rocky supralittoral. J Exp Mar Biol Ecol 105:253-274

Wilson RS, Franklin CE, Davison W, Kraft P (2001) Stenotherms at subzero temperatures: thermal dependence of swimming performance in Antarctic fish. J Comp Physiol B 171:263-169 
Young, Peck and Matheson. Temperature effects on walking and righting.

\section{Figure Legends}

Figure 1. Righting of C. maenas at $10^{\circ} \mathrm{C}$. An animal placed on its dorsal surface (A) moved its fifth pair of pereopods (arrowheads) anteriorly and dorsally $(\mathrm{B}, \mathrm{C})$. The pereopods were rotated $90^{\circ}$ posteriorly $(\mathrm{D}, \mathrm{E}, \mathrm{F})$ rotating the animal in the anterior-posterior plane $(\mathrm{G}, \mathrm{H})$ causing it to right (I). The dashed line represents the point of contact between the animal and the substratum, about which it rotated. Righting was complete when the dactyls of the second pair of pereopods touched the substratum. Images are at $200 \mathrm{~ms}$ intervals. Scale bar, $1 \mathrm{~cm}$.

Figure 2. Righting of L. oceanica at $10^{\circ} \mathrm{C}$. An animal placed on its dorsal surface (A) extended its antennae and uropods while arching its back (B), causing it to roll sideways (C). By pushing against the substratum with its antennae and legs (D), the animal rolled over (E) and straightened (F, G, H). The dashed line represents the point of contact between the animal and the substratum, about which it rotated. Righting was complete when the body was straightened. Images are at $200 \mathrm{~ms}$ intervals. Scale bar, $1 \mathrm{~cm}$.

Figure 3. Righting of $G$. antarcticus at $-2^{\circ} \mathrm{C}$. An animal placed on its dorsal surface (A), extended its fourth pair of pereopods (arrowheads) (B, C), until their dactyls touched the substratum underneath the dorsal surface (D). The animal then pushed against the substratum with this pair of pereopods (E). Once the animal was at an angle greater than $90^{\circ}$ to the substratum $(\mathrm{F})$, the other legs were used to lower the body $(\mathrm{G}, \mathrm{H})$ until the anterior-posterior plane was level with the substratum. The dashed line represents the point of contact between the animal and the substratum, about which it rotated. Righting was complete when the seventh (i.e. most posterior) pair of pereopods touched the substratum. The fourth pair of pereopods is hidden from view in $\mathrm{C}$ and $\mathrm{E}$. Images are at $1 \mathrm{~s}$ intervals. Scale bar, $1 \mathrm{~cm}$.

Figure 4. (A) There was no effect of successive attempts on the time-to-right of $C$. maenas (one way repeated measures ANOVA, $F_{4,16}=2.55, P=\mathrm{NS}$ ) or L. oceanica (one way repeated measures ANOVA, $F_{4,20}=0.42, P=\mathrm{NS}$ ) at temperatures below $1.5^{\circ} \mathrm{C}$, but the time-to-right declined with successive 
Young, Peck and Matheson. Temperature effects on walking and righting.

attempts in $G$. antarcticus (one way repeated measures ANOVA, $F_{4,16}=3.52$, $P<0.05)$.

(B) There was no effect of successive attempts on the time-to-right of $C$. maenas (one way repeated measures ANOVA, $F_{4,16}=0.60, P=\mathrm{NS}$ ) or $G$. antarcticus (one way repeated measures ANOVA, $F_{4,8}=0.40, P=\mathrm{NS}$ ) at temperatures between 1.5 and $5.0^{\circ} \mathrm{C}$, but the time-to-right declined with successive attempts in L. oceanica (one way repeated measures ANOVA, $\left.F_{4,40}=4.38, P<0.01\right)$.

Data are pooled for trials carried out at several different temperatures within the ranges indicated. The mean time-to-right was derived from the mean time per animal per attempt number. Error bars are the standard error of the mean.

Figure 5. The effect of temperature on the mean time-to-right in (A) $C$. maenas $(\mathrm{n}=6),(\mathrm{B})$ L. oceanica $(\mathrm{n}=22)$ and $(\mathrm{C})$ G. antarcticus $(\mathrm{n}=6)$. Mean time-to-right was derived from the mean time per animal per $1^{\circ} \mathrm{C}$ temperature bin. The error bars are the standard error of the mean. Twoparameter single exponential decay functions were fitted to data for $C$. maenas $\left(F_{1,5}=34.78, \mathrm{r}^{2}=0.87, P<0.01\right)$, L. oceanica $\left(F_{1,3}=10.70, \mathrm{r}^{2}=0.78\right.$, $P<0.05)$ and $G$. antarcticus $\left(F_{1,5}=1.0, \mathrm{r}^{2}=0.17, P=\mathrm{NS}\right)$.

Figure 6. (A) The effect of temperature on walking speed, measured in $\mathrm{m} . \mathrm{s}^{-}$ 1 , in C. maenas $\left(F_{2,4}=64.49, \mathrm{r}^{2}=0.97, P<0.001\right) \quad(\mathrm{n}=6), \quad$ L. oceanica $\left(F_{1,4}=35.53, \mathrm{r}^{2}=0.92, P<0.01\right)(\mathrm{n}=17), P . \operatorname{gibber}\left(F_{1,6}=2.76, \mathrm{r}^{2}=0.32, P=\mathrm{NS}\right)$ $(\mathrm{n}=8)$ and $G$. antarcticus $\left(F_{1,6}=4.64, \mathrm{r}^{2}=0.44, P=\mathrm{NS}\right)(\mathrm{n}=17)$. (B) The effect of temperature on mean walking speed, measured in body lengths. $\mathrm{s}^{-1}$, in $C$. maenas $\left(F_{2,4}=51.09, \mathrm{r}^{2}=0.96, P<0.01\right) \quad(\mathrm{n}=6)$, L. oceanica $\quad\left(F_{1,3}=48.07\right.$, $\left.\mathrm{r}^{2}=0.94, P<0.01\right)(\mathrm{n}=17), P$. gibber $\left(\mathrm{F}_{1,6}=9.37, \mathrm{r}^{2}=0.61, P<0.05\right)(\mathrm{n}=8)$ and G. antarcticus $\left(\mathrm{F}_{1,6}=14.98, \mathrm{r}^{2}=0.71, P<0.01\right)(\mathrm{n}=17)$.

Figure 7. Comparison of the effects of temperature on the change in mean walking speed in (A) $\mathrm{ms}^{-1}$ and (B) body lengths. $\mathrm{s}^{-1}$ in the linear part of each species' behavioural response curve, when the effect of body size has been removed. The unstandardised residual for the relationship between body 
Young, Peck and Matheson. Temperature effects on walking and righting.

length and walking speed was calculated (linear regression, walking speed in $\mathrm{ms}^{-1}: F_{1,273}=110.40, \mathrm{r}^{2}=0.29, P<0.001 ;$ body lengths. ${ }^{-1}: F_{1,273}=11.54$, $\left.\mathrm{r}^{2}=0.04, P<0.01\right)$. Slope was calculated by performing a linear regression on temperature versus unstandardised residual (of body length vs. walking speed) for each animal of each species. The $n$ values are the number of animals per species. A circle denotes outliers, which are between 1.5 and 3 times the interquartile range from the quartiles. 
Young, Peck and Matheson. Temperature effects on walking and righting.

Young, Peck and Matheson. Figure 1

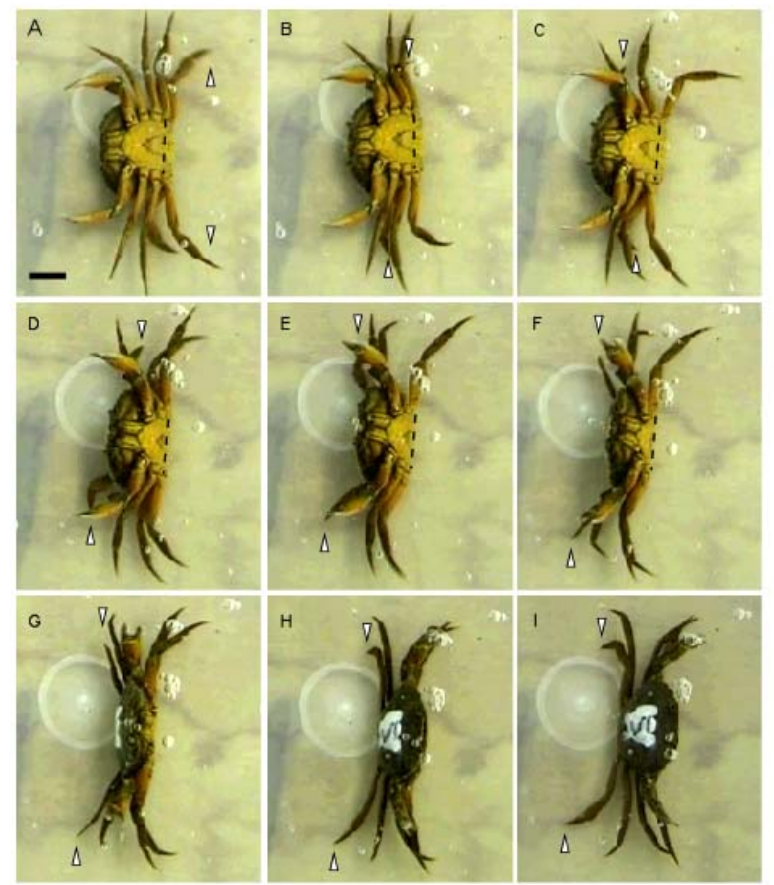


Young, Peck and Matheson. Temperature effects on walking and righting.

Young, Peck and Matheson. Figure 2

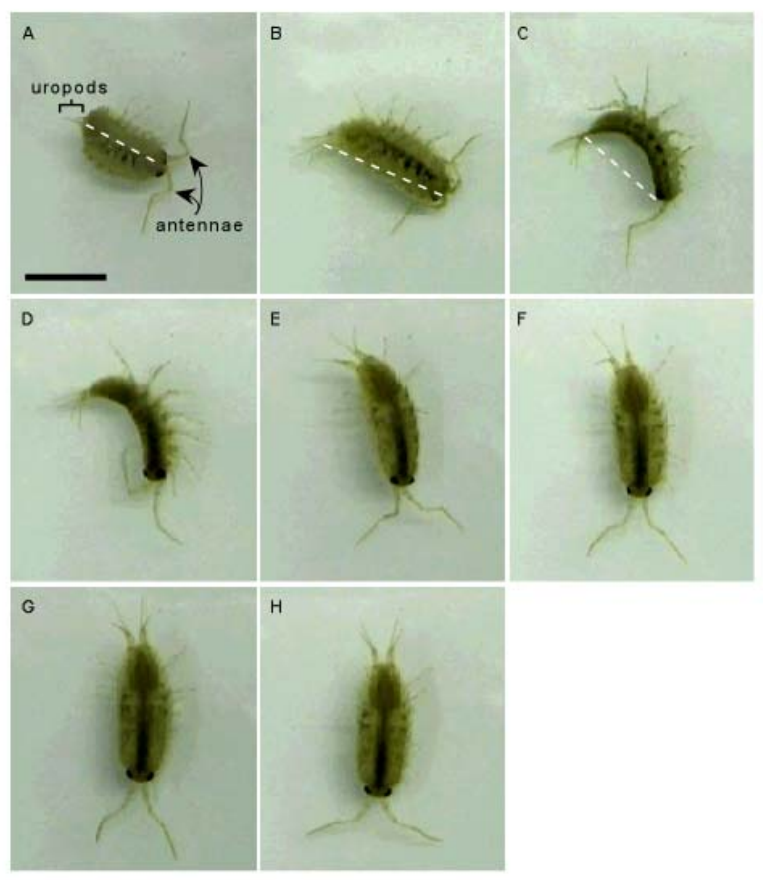


Young, Peck and Matheson. Temperature effects on walking and righting.

Young, Peck and Matheson. Figure 3

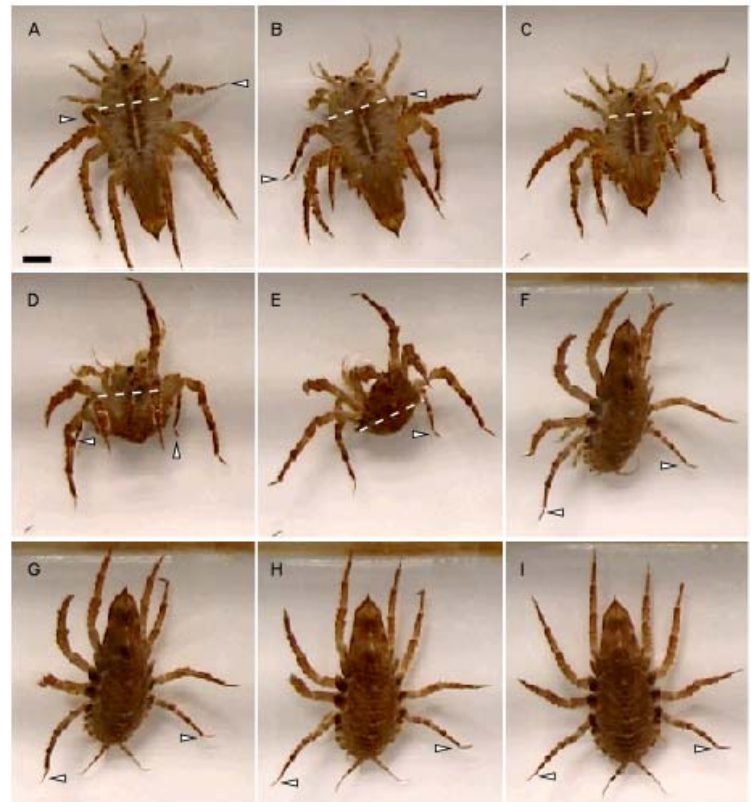


Young, Peck and Matheson. Temperature effects on walking and righting.

Young, Peck and Matheson. Figure 4
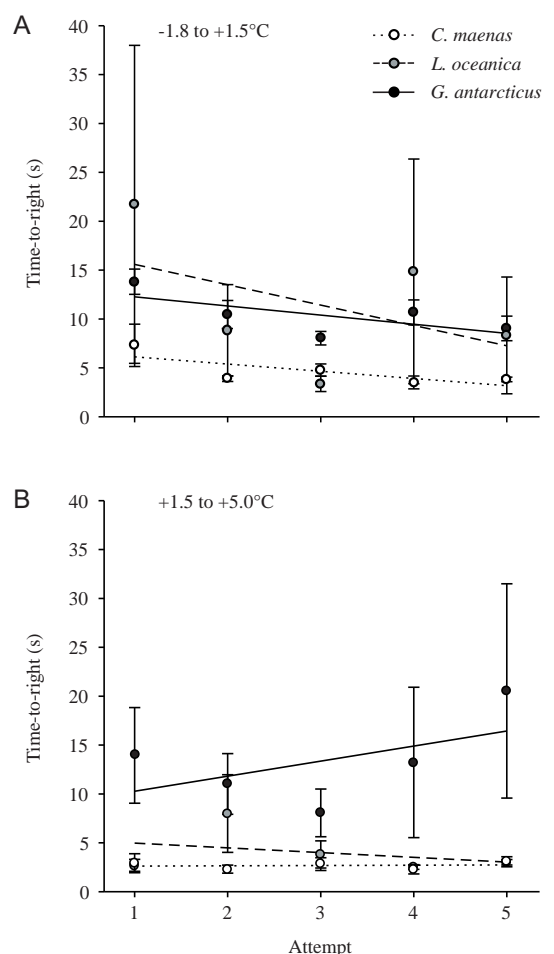
Young, Peck and Matheson. Temperature effects on walking and righting.

Young, Peck and Matheson. Figure 5

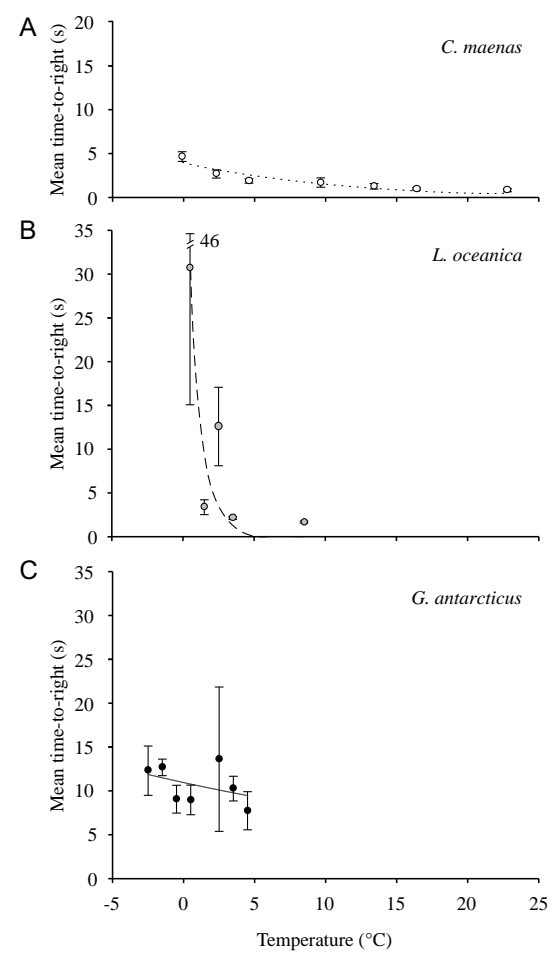


Young, Peck and Matheson. Temperature effects on walking and righting.

Young, Peck and Matheson. Figure 6
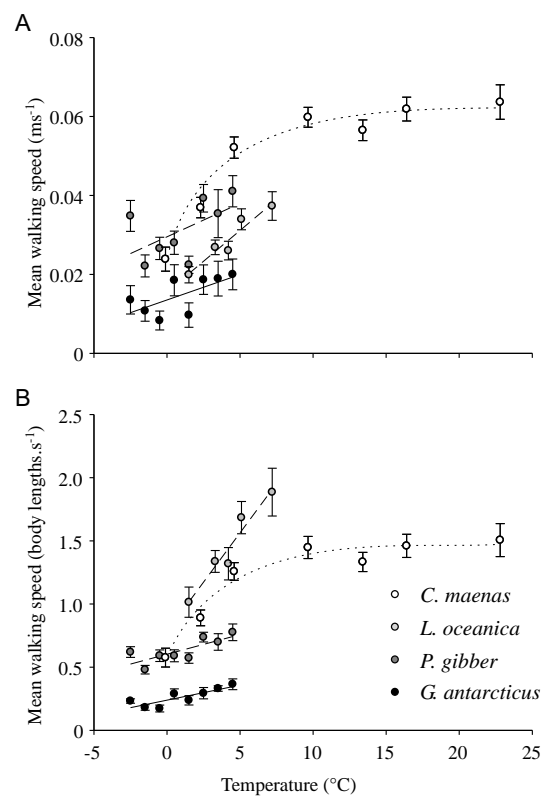
Young, Peck and Matheson. Temperature effects on walking and righting.

Young, Peck and Matheson. Figure 7
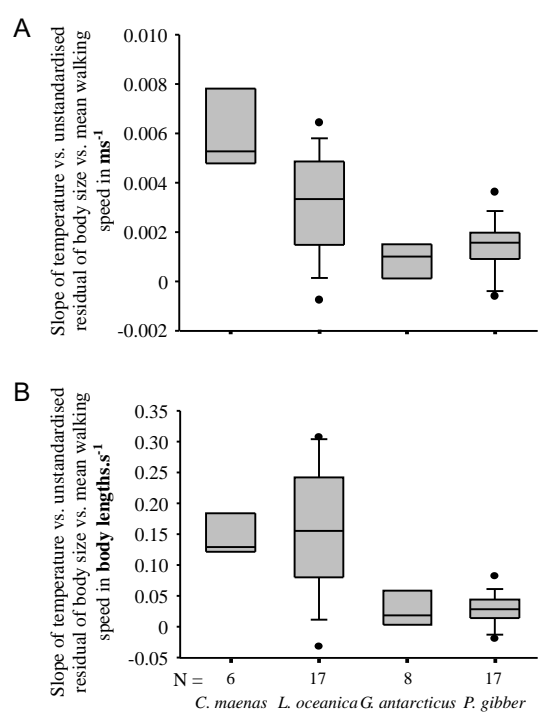